\title{
Compatibility Of The Licensing Of Embedded Patents With Open Source Licensing Terms
}

\author{
Iain G. Mitchell QC, ${ }^{a}$ Stephen Mason ${ }^{b}$ \\ (a) Advocate ; (b) Barrister
}

DOI: 10.5033/ifosslr.v3i1.57

\begin{abstract}
For many years software patenting has been an area of considerable contention, particularly in relation to whether it can, or should, be able to co-exist with Free and Open Source licenses. This issue has gained substantial additional impetus with the publication by the European Commission of the European Interoperability Framework, version 2, which, amongst other objectives, seeks to promote a level playing field for Free and Open Source Software in European public services.

However, interoperability will often require the software to interact with a Standard which contains unavoidable patents.

The issues raised by this were of concern to a client of Andrew Katz ${ }^{1}$, When the client sought the Opinion of Counsel on the matter, Andrew Katz prepared a brief setting out the client's concerns and, by way of illustration, providing the text of a cross-section of commonly-used Free and Open source Software Licences.

The Opinion was issued jointly by Iain G. Mitchell QC and Stephen Mason, Barrister.

The Client has now generously given permission for the Opinion to be published provided that the client's identity is not disclosed. What follows is a suitably edited version of that Opinion, which has been anonymised to respect the wishes of the client and which has been slightly shortened to allow for publication in the Review. ${ }^{2}$
\end{abstract}

Keywords

Law; information technology; Free and Open Source Software; Open Standards; European Interoperability Framework v.2

1 Andrew Katz, Solicitor, of Moorcrofts, Solicitors, James House, Mere Park, Dedmere Road, Marlow, Bucks SL7 1FJ http://www.moorcrofts.com

2 The full (though anonymised) texts of the Brief prepared by Andrew Katz and of the Opinion are available at http://www.ifosslr.org/ifosslr/article/view/57/7 and http://www.ifosslr.org/ifosslr/article/view/57/8 respectively. 


\section{The Context:}

A form of lock-in may arise in the field of interoperability - the capacity of programs and of systems to operate with each other. For example, the keeping confidential of the Source Code relating to a platform, such as Windows, may be used to restrict the ability of other programs (whether themselves proprietary or Open Source) to be developed so as to operate on that platform, and, especially when combined with other practices such as bundling, can amount to abuse of a dominant position, restricting competition. (See, for example, Microsoft Corp. v Commission case T-201/4 at $\$ 1088-$ 1090 of the Judgement dated 17th September, 2007).

Though most obvious in relation to interoperability between programs and platforms, the problem potentially exists to a greater or lesser degree in any situation involving interoperability of programs or systems, and it can readily been seen that a limitation on interoperability can have knock-on effects not only in the realm of competition policy, but also at a functional level where there may be a variety of different systems in different member states which are required to be able to work together.

In order to minimise such problems, at any rate at the level of the EU institutions and the member state governments, there was developed the original European Interoperability Framework (EIF 1), published in 2004, which is more fully described in our Instructions, and to which we refer.

One particular problem recognised by EIF1 is the presence of unavoidable Patents in Open Standards (and, whilst noting the provisions of Directive 98/3, we give "standards" the same extended meaning in the present Opinion as is given in our instructions). This was sought to be addressed by the grammatically inelegant, and almost impenetrable formulation:

"The intellectual property - i.e. patents possibly present - of (parts of) the standard is made irrevocably available on a royalty free basis."

Although the wording is obscure, this could be interpreted to mean that the minimum characteristics required for an Open Standard included that where there were unavoidable patents, licences to permit the programs or systems to utilise the standard should be made available on what is described in the Instructions (at paragraph 6) as "RAND-Z" terms.

This raises two problems in relation to Open Source software. The first, and obvious, problem is the compatibility of Open Source Licensing terms with any standard containing unavoidable patents and, broadly, upon that we are asked to advise. However, there may also be a problem which is inherent in the understanding of RAND terms, and to that we shall also direct our attention.

\section{From EIF1 to EIF2:}

The Instructions were prepared whilst discussions were still in train for the promulgation by the Commission of a new Interoperability Framework, which we refer to as EIF2.

EIF2 was published on 16th December, 2010, as Annex II to Commission Communication Towards Interoperability for European Public Services [COM (2010) 744 final]. So far as material to the 
present issue, paragraph 5.2.1 of the Communication requires, inter alia:

"Intellectual property rights related to the specification are licensed on FRAND terms or on a royalty-free basis in a way that allows implementation in both proprietary and open source software."

"FRAND" is defined in footnote 19 as "Fair, reasonable and non-discriminatory"; and this particular provision is justified in footnote 20 thus:

"This fosters competition since providers working under various business models may compete to deliver products, technologies and services based on such specification."

The intent which lies behind the provision referred to in paragraph 5.2.1 could not be more clear: interoperability requires a level playing field between Proprietary and Open Source Software. What, however, may be in issue is the extent to which this intention has been translated into the working of the real world. It is to that question that the present Opinion is directed.

\title{
3. The Legal Standing of EIF2:
}

Whereas there was a sense that EIF1 was developed from the bottom up by individuals and bodies and at least elements from within the Commission, there is more of a sense of EIF2 being directed from the top. This reflects an acknowledgement by the Commission of the critical importance to the Union of efficient interoperable systems in the public sector across Europe, and may perhaps be seen as a winning of hearts and minds by the pioneers who developed EIF1.

This becomes clear in the opening paragraph of Commission Memo/10/689 of 16th December, 2010:

\begin{abstract}
The need for effective interoperability is at the centre of the Digital Agenda for Europe (see IP/10/581, MEMO/10/199 and MEMO/10/200), one of the flagship initiatives in the Europe 2020 Strategy. In the case of public administrations, effective interoperability is vital to ensuring that they can provide efficient, effective cross-border eGovernment services, as reflected in the eGovernment Action Plan just adopted by the Commission (see IP/10/1718). As part of the Digital Agenda and the eGovernment Action Plan, the Commission committed itself to adopt in 2010 a Communication that introduces the European Interoperability Strategy (EIS) and the European Interoperability Framework (EIF), two key documents to focus our efforts and work via a common approach to achieve better interoperability for European public services. They complement the Digital Agenda for Europe in establishing a common approach for Member States' public administrations, to help citizens and businesses to profit fully from the single market.
\end{abstract}

However, the European Union has no treaty competencies in the area of the organisation and delivery of public services (though the procurement of such services may engage Treaty and derived principles). Consequently, it is not possible for the EU to legislate (for example by way of Directive or Regulation) in the area of interoperability of systems for the provision of public services, and instead the Commission was required to promulgate the Strategy and Framework documents by way of a Commission Communication. 
It is easy to focus on what a Communication is not - it is not law; it is not binding on anyone; it cannot be legally enforced; it does not, in its terms, extend beyond the public into the private law realm; it is not a formal standard. However, this is to underplay its moral authority - it is a communication proceeding from the Commission and has the full weight of the Commission behind it; it would be highly persuasive in the event that it comes to be considered by the courts, for example in a public procurement exercise and, as is apparent from the Memo, it is the result of intensive consultation amongst all of the parties at European and member state level. In short, it has considerable intellectual and moral authority, even if it lacks direct legal enforceability.

In these circumstances, though there is no legal imperative upon Member States to implement EIF2 so as to provide compatibility at national level within those States, this is the clear intention as confirmed in the Communication:

"Member States should..... align their national interoperability frameworks with the EIF".

This was endorsed in the Malmo Ministerial Declaration of 18th November 2009, and in the Communication accompanying the eGovernment Action Plan 2011-2015 of December 2010, when this action was formally targeted for achievement by 2013. It may also be hoped that there will come to be some "leakage" from the public to the private sphere. In short, EIF2 is immensely more authoritative than was EIF1.

\section{Do existing Open Source Licences allow EIF2 to be given effect so as to allow Licensees to use the Licensed Software where unavoidable Patents are present, but Licences are available on RAND Terms?}

(a) Context - A health warning:

Typically, Open Source Licences contain no choice of law provisions and, if and when a dispute arises, will fall to be interpreted by the court before which the litigation proceeds.

Given the international nature of most Open Source software, with, it may be, contributions from developers in multiple jurisdictions, and the possibility that the parties may each, themselves, be domiciled in different jurisdictions, ascertainment of the applicable law may be no easy question in any given case, quite apart from then applying that law, which may not be the same as the law of the forum.

Usually, and in the absence of the matter being focused by the parties, the court will either apply the domestic law of the forum, or if it is contended that the proper law of the contract is (say) the law of California, the court will apply the presumption that the law of the foreign state is the same as the domestic law, unless the parties aver (and, as a matter of fact, not law) prove otherwise.

To some extent the problem is masked since it is, of course, the words of the licence which govern its terms and, simplistically, one might think that the words would be interpreted in the same way, whatever the governing law, but this should by no means be assumed. Furthermore, even if the words 
themselves receive a uniform interpretation, it does not follow that they will receive a uniform effect. For example, a common feature of Open Source Licences is a term purporting to exclude liability. It is not to be ruled out that, in a particular licence, technical words might be used having a different meaning in different jurisdictions, but, even assuming that it is clear what the words mean, the court might refuse to give effect to the provision excluding liability, or treat it as pro non scripto or even, in an extreme case, decline to enforce the entire licence - it all may depend on what the domestic law provides in respect of the validity and/or enforceability of clauses excluding liability.

It is understood, however, that the omission of a choice of law clause by the drafters of the GPL was deliberate.

Although a detailed consideration of this topic lies outside the scope of the present Opinion, it should be recognised that what we say about the meaning of the various licences and how they relate to the EIF2 is always subject to the caveat which we have just expressed.

\section{(b) Interaction with Patent Licences:}

Where there is an unavoidable patent embodied in a standard, then, if a software developer writes software to operate with the standard, that will give rise to an infringement of the patent, unless the patent owner grants permission for the patent to be used, which is to say, licences the patent to the developer.

How that is sought to be achieved we discuss more fully below when we come to discuss RAND licensing of patents, but for the present, we observe that, typically, the patent owner will licence the patent to an individual licensee who will not be allowed to sublicense or assign the benefit of the licence to another person. This is of some importance given the licensing models employed in Open Source software: Developer A creates the software, and owns the copyright in it; since it interacts with an unavoidable patent, he obtains a RAND licence for that patent from X, the patent owner. A then licenses the copyright in his program to developer B under an Open Source Licence, but will normally not be able to assign the licensee's rights under the patent Licence. Accordingly, developer $\mathrm{B}$ will require to obtain from $\mathrm{X}$ a separate patent licence. (Whether this is indeed the result will, of course, depend upon whether the original patent licence in favour of $\mathrm{A}$ is, in its terms, assignable).

In these circumstances, it is likely that licensing of software under Open Source Licences will not carry transferability of patent licences. Were it not for the analysis set out below of the particular terms of certain restrictive Open Source licences, this would have been little more than merely inconvenient, assuming (as EIF2 mandates) that patent licences would have been available to all comers on RAND terms.

\section{(c) Permissive Licences:}

As explained in the Brief, permissive licences are seldom concerned to do other than ensure that source code and, consequently, the corresponding object code may be used with minimal restrictions. Commonly, those restrictions include (but seldom extend beyond) the following requirements:

1. Whatever the form of licence, the user is required to display notices indicating 
ownership of the intellectual property rights.

2. An assertion is made that the software is provided without warranty as to fitness for purpose and limitation of liability.

(Where what we have termed a "permissive licence" contains terms specifically dealing with patent issues, we have adopted the terminology "hybrid licence", and comment on these in the following section).

In these circumstances, one would be surprised to find any impediment to the use of Open Source software even in the presence of unavoidable patents in the relevant standard. Of course, each such Licence will fall to be interpreted according to its terms, but such licences as have been exhibited to us present no apparent problem. In particular:

\section{(i) MIT (X11) License:}

This contains no provision inimical to the use of software licensed thereunder in conjunction with an unavoidable patent (whether or not RAND Licensed).

\section{(ii) BSD License:}

This contains no provision inimical to the use of software licensed thereunder in conjunction with an unavoidable patent (whether or not RAND Licensed).

\section{(iii) Perl Artistic License 1:}

This contains no provision inimical to the use of software licensed thereunder in conjunction with an unavoidable patent (whether or not RAND Licensed).

\section{(d) Hybrid Licences:}

Certain of the permissive licences we have seen do include terms which touch on patents. In this regard, we refer to the following:

\section{(i) Perl Artistic License 2.0:}

Clause (13) is what amounts, in substance, to a licence by the granter to the licensee of any patents to which the granter has right, coupled with a termination of the licence in the event that the licensee institutes proceedings for patent infringement.

However, it cannot extend beyond "patent claims licensable by the Copyright Holder that are necessarily infringed by the package". In view of the explanation, which we give at part 4(1)(b) of the present Opinion, this would not generally include unavoidable patents licensed to the granter by the patent owner. It is more properly directed at a situation in which the granter might have incorporated patented material in his own work, and it merely provides that if the grantee raises any litigation in which he (the licensee) claims that the package (the program) constitutes patent infringement, the 
licence in favour of the licensee is terminated. Typically this will affect (but is not limited to) an attempt by the licensee to bring about downstream enforcement of patents by the licensee.

Thus, so far as is material to the present discussion, this licence is seen to be a permissive licence akin to the other permissive licences discussed above.

\title{
(ii) Apache Public License:
}

Clause 3 is of similar effect to clause 13 in the Perl 2 License. The Apache Public License is, in the same way, a permissive licence.

\section{(e) Restrictive Licences:}

Restrictive Licences often come with an agenda attached. In particular, their drafters are frequently opposed to software patents, or, at any rate, see the presence of software patents as being inimical to Open Source software, perhaps leading to proprietarisation by the back door. Accordingly, they frequently seek to use their licensing terms in order to prevent this.

This approach is explained in the preamble to the GPL 2.0:

\begin{abstract}
"Any free program is threatened constantly by software patents. We wish to avoid the danger that redistributors of a free program will individually obtain patent licenses, in effect making the program proprietary. To prevent this, we have made it clear that any patent must be licensed for everyone's free use or not at all."
\end{abstract}

Taking this policy statement at face value, it contains a major and a minor premise which are not necessarily consistent with each other. In that it is the objective of FRAND Licenses to make a patent available for the free use (and, in the case of FRAND-Z Licences, free in both senses of the word) of each licensee and if it be that case that a Patent holder could not refuse to make a patent licence available to an applicant, then that would have achieved the result of making the patent freely available for everyone's use. However, the preceding sentence appears to proceed on the basis that any requirement for an individual to obtain an individual patent licence is inimical to free software.

It might be that we can go some way to analysing that tension if we consider the fundamental architecture of the open source software licensing model, and in particular the GPL family of licences.

\section{(i) GNU General Public Licence 2.0:}

The architecture of the GPL 2 is typical of restrictive Open Source Licences. It includes the following elements:

1. It applies to "any program or other work" which has been distributed under the terms of the GPL2 licence (clause 0);

2. It is clear from clauses 1 and 2 that the licence is a copyright licence; 
3. The user may copy and distribute verbatim copies of the Program's source code as they receive it, in any medium (clause 1);

4. The user may modify the copy or copies of the Program or any portion of it, thus forming a work based on the Program, and copy and distribute such modifications, subject to the requirement that the person notifies subsequent users of the modified program, and enables the next users to license the program to third parties at no cost (clause 2);

5. There is no requirement to sign the licence, but the user is deemed to accept the terms of the licence if he modifies or distributes the program (clause 5);

6. Clause 6 is fundamental to the architecture of GPL licensing. It provides:

"Each time you redistribute the program (or any work based on the program), the recipient automatically receives a license from the original licensor to copy or modify the program subject to these terms and conditions. You may not impose any further restrictions on the recipients' exercise of the rights granted herein...."

The model is that when developer A transmits the modified work to developer B, he is neither sublicensing nor assigning the licence granted to him by the original developer of the program; rather, there is said to be created a fresh grant from the original developer to developer B, with a separate grant of a licence by developer A to developer B of his works of modification. There are stray references in GPL2 to sub-licensing, but GPL3 (which we consider more fully below) is more explicit: the final sentence of clause 2 states: "Sublicensing is not allowed; section 10 makes it unnecessary". Section 10 provides:

"Each time you convey a covered work, the recipient automatically receives a license from the original licensors to run, modify and propagate that work, subject to this License".

It will also follow that there will be a similar "automatic licensing" of the modifying work by Developer B.

Under the FRAND Licensing model, it will usually be the case that although each licensee will be able to obtain his own individual licence from the patent owner, the process does not have the same automaticity in respect of downstream users as is involved in the GPL Licensing model.

(As we discuss later, this may not always be the case, but for present purposes we assume it to be so);

7. The licence purports to prevent the distribution of the program by the licensee where, by reason of a court judgement or for any other reason the licensee's distribution is subjected to conditions which would contradict the conditions of the licence (clause 7);

8. Where distribution or use of the program is restricted because of patents or copyrighted interfaces, the original owner of the intellectual property who decides to put his property under the terms of the licence may place limitations on the geographical distribution of the program (clause 8);

There is no clause relating to governing law and jurisdiction, and many of the words and phrases may 
be construed differently in different jurisdictions.

Against the background of the drafter's assumption as to the two Licensing models (Open Source and FRAND), the crucial provision is seen to be condition (b) of clause 2:

"You must cause any work that you distribute or publish, that in whole or in part contains or is derived from the Program or any part thereof, to be licensed as a whole at no charge to all third parties under the terms of this license."

This interacts with clause 7 to prevent a person from distributing the program where distribution cannot be achieved in accordance with this condition.

At first sight, it might be thought to be arguable that all this means is that the copyrighted work should be (copyright) licensed as a whole to all third parties and without charge. This view is arguably reinforced by the terms of clause 0 , which provide:

'This License applies to any program or other work...... The 'Program', below, refers to any such program or work, and a 'work based on the program' means either the program or any derivative work under copyright law..."

If clause 2(b) were to be interpreted as solely relating to the distribution of a work free of copyright royalty then condition 2 (b) would be satisfied, even although there might be a need to pay a royalty to the holder of a patent, and even although the granter of the GPL2 licence of the copyright work might not be in a position to grant to the licensee a licence of any unavoidable patent.

However, we are not persuaded that clause 2(b) has only this limited effect. The problem lies with the wording of clause 7 .

There is clearly no question that clause 7 effectively prevents distribution of the work where conditions are imposed on the licensee preventing him licensing the copyright in the work without charge. For example, say that the work contains some lines of proprietary code, the licensee is sued by the proprietary copyright holder, and the action is settled by means of imposing on the licensee an obligation to extract a royalty and remit it to the proprietary copyright holder. In that situation, clause 7 would clearly be effective. However, the example contained within clause 7 is wider than that:

"For example, if a patent license would not permit royalty free redistribution of the Program by all those who receive copies directly or indirectly through you, then the only way that you could satisfy both it and this License would be to refrain entirely from distribution of the program."

On the face of it, this appears to prevent distribution of the program where a patent royalty is payable. How to resolve this apparent conflict?

One way is to say that the example is only an example and does not purport to be an operative provision: it is possible that it is merely a misunderstanding of the effect of the operative provision. This is not an entirely happy analysis, as the court will endeavour to interpret the Licence as a whole. A court is unlikely to be impressed by the circular argument that the example is indeed consistent 
with clause 2(b) as the example refers only to "royalty free distribution" and, in the context of the entire licence, this means free of copyright royalties, not free of patent royalties. The problem is that for the example to have any meaning, it would be necessary to imagine a situation in which a patent might prevent the copyright in a work being licensed without payment of a royalty for the licensing of the copyright, and we confess that this is difficult to envisage.

More tellingly, if we recollect the policy statement which appears in the preamble, read along with the exposition of the fundamental architecture set out in clause 6 , it becomes clear that the reference in clause 0 to "copyright law" does not define the limit of applicability of the GPL 2 Licence, but merely (as a matter of grammatical construction) relates only to a derivative work - i.e. to be a "derivative work" for the purposes of the licence, the work should also be a "derivative work" for the purposes of copyright law. This is reinforced by the reference in clause 2(b) to "licensed as a whole" [emphasis added]. Interpreted in that manner, the apparent conflict between clause 2(b) and the example disappears: the whole Licence terms do make internal sense - if the granter of the GPL licence cannot provide the same automatic downstream cascade of patent rights as he can in respect of copyright, he cannot grant a GPL copyright licence. Because this would permit a court to construe the licence as a whole and without internal conflicts, we suspect that it would be the interpretation which would be likely to commend itself to a court.

Consequently, the likelihood is that if a third party were to require to obtain from the Patent Holder of an unavoidable patent a licence of that patent on terms that were other than royalty-free, then clause 7 would be effective and the licensee under the GPL 2 licence would be prevented from distributing the work at all.

Therefore, it is probable that the GPL2 Licence would not be capable of allowing programs licensed thereunder to interoperate with EIF2, where there are unavoidable patents licensed on FRAND royalty-payable terms. Even in relation to RAND-Z licences, there may be potential problems. First, although, if no royalty is payable for the patent licence, there will not be an incompatibility with condition 2(b) of GPL2 in relation to the use of the software to implement the standard, the RAND$\mathrm{Z}$ licence may not permit the licensee to develop a derivative work which, though still infringing the patent (absent a licence), did not do so for the purpose of implementing the standard. In other words, the licensee under the GPL licence may be unable to licence the work "as a whole at no charge to all third parties," in particular, those third parties who might seek to develop the software for a reason other than interacting with the standard.

A further issue in relation to RAND-Z licences is that, under clause 2(b) what should be licensed at no charge to all third parties is the work "as a whole." It is at least arguable that clause 2(b) is not just about charging (though that is the thrust of the example), but sets out a test which is cumulative. There are 3 requirements, each of equal importance: first, the work as a whole should be licensed; second, the licence of the work as a whole should be without charge, and, third, it should be so licensed to all third parties. If a court were to regard the work "as a whole" as including that part of the work as would (absent a patent licence) infringe an unavoidable patent, then the licence of the work as a whole should include a patent licence in respect of that unavoidable patent.

The logic of the preamble read along with clause 6 would favour such an interpretation, and, in these circumstances there is a strong chance that a court, interpreting the GPL License purposively would 
regard even FRAND-Z Licences as being incompatible with the GPL2.

There is an additional quibble that clause 2 (b) commences "you must cause any work... to be licensed as a whole" [emphasis added]. If licensing of unavoidable patents on FRAND-Z terms were otherwise compatible with GPL2 (as to which, see the previous paragraph) then such compatibility would arise inherently in the system rather than be caused by the licensee. However (and in the event that FRAND-Z licensing is otherwise compatible), we have no doubt that the court would give a purposive interpretation to this clause and, providing the result were achieved, would treat it as irrelevant how it came to be achieved.

Further uncertainty arises from the possibility that GPL 2 may be interpreted differently in different jurisdictions. For example, some jurisdictions (including England \& Wales and Scotland) will seek to apply the contra proferentem rule and may reach a different interpretation from jurisdictions where such a rule does not apply; or in some jurisdictions, it is competent for the court to hear evidence in order to ascertain the context in which the licence falls to be interpreted (See Profile Software Ltd v. Becogent Ltd [2005] ScotCS CSOH 28 (16 February 2005)). In relation to the incompatibility of GPL2 with FRAND royalty payable licences, we do not think that such potentially differing approaches are likely to make much, if any difference; but in relation to the compatibility of FRAND$\mathrm{Z}$ licences and the GPL2 it might be crucial, since a purposive interpretation may hang on questions of context and proferens.

In short, even if the licensing of a patent embedded in a standard were to be on royalty free FRAND terms, it is arguable that clause 7 would still prevent distribution of the work as the conditions imposed in that clause are apparently cumulative and not alternative.

\section{(ii) GNU Lesser General Public License 2.1:}

This licence applies to "the Library" which is defined as "a collection of software functions and/or data prepared so as to be conveniently linked with application programs, and which has been distributed under the terms of the GPL2 licence" (clause 0).

Although the wording differs in detail in several places and the paragraph numbering is different, the clauses with which the present Opinion is concerned are in substantially the same terms as the GPL 2 Licence and would, in our view, lead to the same outcome.

\section{(iii) GNU General Public License 3:}

The GPL 3 is much more detailed in its terms, though, as noted in connection with the GPL2, there is no clause relating to governing law and jurisdiction, and we should therefore once more warn that it is possible that some of the words and phrases may be construed differently in different jurisdictions.

Subject to that caveat, it is clear from the Introduction what the intent of the author is. The last paragraph of the Introduction states:

"Finally, every program is threatened constantly by software patents. States should not 
allow patents to restrict development and use of software on general-purpose computers, but in those that do, we wish to avoid the special danger that patents applied to a free program could make it effectively proprietary. To prevent this, the GPL assures that patents cannot be used to render the program non-free."

We are struck not by the similarity of this statement to the equivalent statement in GPL2, but by the difference between them. The two statements are the same except for the last sentence, which, in the GPL2 is as follows:

"To prevent this, we have made it clear that any patent must be licensed for everyone's free use or not at all."

In GPL3 it states:

"To prevent this, the GPL assures that patents cannot be used to render the program nonfree."

This may suggest a change of emphasis between GPL2 and GPL3, which, it may be, is reflected in the clause of GPL3 specifically applying to patents, clause 11, which provides (inter alia):

"If you convey a covered work, knowingly relying on a patent license, and the Corresponding Source of the work is not available for anyone to copy, free of charge and under the terms of this license, through a publicly available network server or other readily accessible means, then you must either (1) cause the Corresponding Source to be available, or (2) deprive yourself of the benefit of the patent license for this particular work, or (3) arrange, in a manner consistent with the requirements of this License to extend the patent license to downstream recipients."

At first sight, this provision, in spite of the reference to "knowingly relying on a patent license" appears to relate to ensuring that the Source Code is kept open and available to downstream recipients, and it may be possible to hypothesise a situation in which the source code is made freely available by the owner of the work, who derives his proprietary protection from the Patent only, with the result that this part of clause 11 would not be engaged as it is concerned with source code only. However, there is an argument that clause 11 is wider in its scope and does engage with licenses of embedded patents. This issue is thrown into relief when we come below to consider typical FRAND Licences.

The Licence will fall to be interpreted as a whole. The following clause (clause 12), widely known as the "liberty or death" clause, is headed "No surrender of others' freedom" and it makes it clear that if any conditions are imposed on the licensee which make it impossible for him to convey a covered work without satisfying his obligations under the GPL3, then he is prevented from conveying the work at all.

Furthermore, footnote 89 of the GPLv3 Second Discussion Draft Rationale document states:

"After gathering opinion on the second paragraph of section 11 during the discussion process, we decided to offer a specific form of shielding that would satisfy the objectives of 
the paragraph. A distributor of a covered work under benefit of a patent license can ensure that the Corresponding Source is made publicly available, free of charge, for all to access and copy, such as by arranging for the Corresponding Source to be available on a public network server. We keep the more general shielding requirement as an option because we do not wish to insist upon public distribution of source code. Distributors complying with this section may prefer to provide other means of shielding their downstream recipients."

Although the precise drafting of clause 11 was altered in the final version, the GPLv3 Third Discussion Draft Rationale (Free Software Foundation, 2007) states, at §3.4:

"Previous drafts of GPLv3 included a "shielding" provision in section 11, which we have further refined in Draft 3; it is now found in the third paragraph of section 11."

This explanation appears to reflect an implicit assumption that, by making the source code generally available, so also is the patent licence made generally available. As is apparent from our explanation of the terms of the GPL2, such an assumption is not generally warranted, as, in the usual case of a FRAND licence, there will not be a general downstream transmission of the benefit of the licence. It may, however, be that this assumption has been reflected in the wording of clauses 11 and 12 as finally published.

It is, of course, the wording of the licence itself to which a court in England or Scotland will first address itself. If, as a matter of grammatical construction, the wording is clear, then the court will not have regard to any extrinsic evidence (including the paragraph headings in the Licence and any drafting documents, such as the published rationale documents). The key question is, thus, what do the words themselves say?

It will be noted that the requirement of the part of clause 11 to which we refer is threefold: first, that the Corresponding Source should be available on a publicly available server or other readily accessible means, second, that it should be available to copy free of charge, and, third, that it should be made available "under the terms of this licence" [emphasis added]. If not so available, the Licensee has to arrange to extend the patent licence to downstream recipients, but this must be "in a manner consistent with the requirements of this License" (notably, free of charge), or else the Licensee has to deprive himself of the benefit of the patent licence for the work - in other words not to distribute it (since to do so without benefit of the patent licence would not be possible without infringing the patent).

At first blush, therefore, if the source code is available to be copied by anyone free of charge and that copying of the source code is under the terms of the GPL3 licence, then the conditions of clause 11 are satisfied. That would be so, even though there might be a requirement for a third party downstream to obtain a Patent Licence in respect of an embedded patent. This interpretation (which is actually what the words say) would plainly not prevent the distribution of the software even where a patent licence might be required (at any rate save in the extremely rare case where the Patent itself contains lines of code which are transcribed into the work licensed under the GPL3).

In response to this, it might be pointed out that clause 12 contains a prohibition on distributing the work where the distributor cannot satisfy his "obligations under the licence". It would then be 
suggested that to distribute the work where the transferee would require to obtain a FRAND licence would be a "surrender of others' freedom" and so, not consistent with the obligations under the licence. That interpretation (as a matter of strict construction) is not tenable. The heading of clause 12 (as we have pointed out) is not an operative provision of the licence. Clause 11 is an operative provision. Thus (with a neat circularity) distribution in accordance with clause 11 is not distribution in breach of the licence terms, so there is no breach of the requirement of clause 12.

We have little doubt that this is not what the drafters of the GPL3 meant, but it is what they said, and a document is interpreted according to what it says, not what its drafters meant.

Of course, the anomaly arises by reason of the implicit, but unwarranted assumption, referred to above, that publication of the source code so as to make it generally available also serves to make the patent licence generally available. If that were the case, the anomaly disappears. By making the source code available in terms of clause 11 , so, too is the patent licence made available. Thus the patent licence would have been made available under clause 11 and (in terns of clause 12) there would have been a distribution under the terms of the GPL3 Licence, which, neatly would not have involved the surrender of the freedom of others.

The issue, acutely, becomes whether a court would consider that there was such ambiguity in the terms of the licence as to require it to have regard to extrinsic evidence. If there were such ambiguity, the extrinsic material would support an intention to prevent distribution where there are unavoidable patents licensed on FRAND terms; but if no regard is had to the extrinsic evidence, the words of clause 11 would have the opposite effect.

Even if clause 11 is interpreted strictly, there are still issues which may arise in relation to whether the making of the source code available on the terms stipulated in that clause would always permit the distribution of software where there is an embedded patent. A later sub-clause of clause 11 defines a "discriminatory" patent licence as one which (in effect) frustrates the exercise of any rights which are granted under the GPL3. However, we note that this sub-clause does not in terms prohibit the granting of discriminatory licences. What it does do is to forbid the licensee from "conveying" a work covered by the GPL3 to another where: first, the Licensee pays a royalty related to the extent of the licensee's conveying of the work; second, the third party to whom that royalty is paid is in the business of distributing software, and, third the persons who are downstream receive a discriminatory patent licence. It is easy to figure that any such licence as would be granted by the patent holder runs a risk of being regarded as "discriminatory" as specially defined in the GPL3 - for example, if the downstream recipient had to pay a further royalty, or if there was (as there almost certainly would be) imposed a restriction on transmissibility further downstream. There is a saving for such agreements made prior to 28th March, 2007.

It may be that the terms of this sub-clause should be seen in the light of the announcement made by Microsoft and Novell in November 2006 of a broad collaboration between them on Linux interoperability and support, and whatever the compatibility of elements of that collaboration and the terms of the GPL2, the sub-clause is making clear that under the GPL3, from the date that it was promulgated, it would not be permissible in certain circumstances. This is achieved by defining the circumstances in which such a royalty would be permissible. Thus, in terms of the sub-clause, one might, for example, have a royalty (payable even to Microsoft) which is not related to the activity of 
conveying the work, or one might have a royalty related to the activity of conveying, provided it were not to a third party in the business of distributing software, or, indeed, one might have an arrangement which offended against all three of the principles, so long as it were made prior to 28th March, 2007.

It may be that a further impediment to distribution where there is an unavoidable patent could arise in another way as a result of the application clause 12, which, as noted above, makes it clear that if any conditions are imposed on the licensee which make it impossible for him to convey a covered work without satisfying his obligations under the GPL3, then he is prevented from conveying the work at all.

So, what are the other obligations under the GPL3 which might be rendered impossible by the existence of a FRAND patent Licensing regime?

Clause 5 (c) provides:

"You must license the entire work, as a whole, under this license to anyone who comes into possession of a copy."

This echoes the wording of clause 2(b) of GPL2:

"You must cause any work that you distribute or publish, that in whole or in part contains or is derived from the Program or any part thereof, to be licensed as a whole at no charge to all third parties under the terms of this license."

As with the GPL2, clause 5(c) of GPL3 requires the work to be licensed: first, "as a whole"; second "under this license" and, third, it should be licensed to "anyone who comes into possession of a copy", (which we take to be merely a clearer exposition of "all third parties" in GPL2). The only material difference is the omission of "at no charge".

It appears to us that the same comments that we made in relation to the proper interpretation of clause 2(b) of GPL2 apply mutatis mutandis to clause 5(c) of GPL3. Accordingly, notwithstanding the specific provisions directed at patent licenses, a substantial problem may arise from the provisions of clause 12 read along with clause 5(c): the fundamentally different architecture of downstream licensing under GPL3 is likely to be regarded as incompatible with the need for the individual direct licences which require to be granted under FRAND Licences.

In conclusion, therefore, although a literal reading of clause 11 of the GPL3, even read in conjunction with clause 12, would appear to permit transmission of a covered work where is a requirement upon a third party to obtain a patent licence, such a reading would be controversial. If challenged in court, there is some risk that the court may have regard to extrinsic evidence to interpret clauses 11 and 12 (and the risk may vary in different jurisdictions, depending on the domestic law as to the interpretation of documents) and, if the court did have regard to such evidence, there would be a high risk that the court would interpret the licence provisions so as to prevent transmission in the face of the need to obtain a patent licence. Furthermore, even on a literal reading of clause 11, problems arise in relation to compatibility with clause $5(\mathrm{c})$. This may be fatal to allowing transmission where a patent licence was required, but, even if not itself fatal, would certainly provide a basis for finding 
that there was ambiguity as to the construction of the GPL3 as a whole, thus opening the door to extrinsic evidence, with the effect referred to above.

In short, it would not be safe to rely upon the GPL3 as being consistent with the FRAND licensing of embedded patents.

\section{(iv) GNU Lesser General Public License, Version 3.}

This licence is a variant of the GPL3. In form, it consists of certain listed modifications and variations to the GPL3. None of the special terms of the GNU Lesser General Public License would appear to affect the provisions upon which we comment in the previous section of this Opinion and, accordingly, our view remains as expressed in respect of the GPL3.

\section{(v) European Union Public Licence v 1.1}

A substantial problem with the GPL is the mutual incompatibility of copyright licensing under the GPL and FRAND licensing of patents, which incompatibility is brought into play by the clauses in the GPL family of licences which effectively require that the patent licensing architecture has to conform to the GPL architecture.

No such problem would exist in the absence of such clauses (even though a fundamentally different architecture of patent and copyright licensing still existed).

This is illustrated by the EUPL, and in particular a sub-clause of clause 5 (called the "copyleft clause") which makes no such requirement in relation to the licensing of patents. Looking more closely at the EUPL, one sees that by the final provision of clause 2 of this licence, "the Licensor grants to the Licensee royalty-free, non-exclusive usage rights to any patents held by the Licensor, to the extent necessary to make use of the rights granted on the Work under this Licence".

As will become apparent, the typical architecture of a FRAND Licence of an unavoidable Patent will prevent the Licensor of the program (who is also a Licensee of the patent) from sub-licensing or assigning the benefit of his patent licence, but this raises no issue with respect to interoperability since, of course, the scope of clause 2 extends only as far as relating to patents of which the Licensor (under the EUPL) is the owner of the patent. Therefore, it will clearly be for the Licensee of the program to obtain his own FRAND Licence of the unavoidable patent from the owner of that unavoidable patent.

Slightly more problematic is clause 3 which in certain circumstances obliges the Licensor to make available either the Source Code or a repository where it is "easily and freely accessible". Where an issue may arise is, in those extremely rare cases where the unavoidable patent contains actual source code which belongs to the Patent Holder, and where the patent holder has granted only a limited right to access or distribute that source code. Quaere whether that source code is "easily and freely accessible" to a licensee under EUPL if, in order to be able to access and distribute it, the Licensee requires to obtain his own FRAND Licence from the Patent owner. We have discussed this issue more fully above in connection with the GPL licences where the problem arises particularly acutely, but for the purposes of the present discussion, if the Licensee has a right to access to the source code 
entailed in the patent on FRAND terms, then, on balance we are satisfied that this would meet the EUPL requirement for that source code to be "easily and freely accessible". We do not consider that it makes any material difference whether the FRAND Licence is FRAND-Z or royalty payable, as "freely" would be fall to be construed eiusdem generis with "easily", as meaning without undue restriction, rather than free of charge.

On balance, therefore, it is unlikely that there is any conflict between FRAND licensing of unavoidable patents and the terms of the EUPL.

\section{Potential Points of Conflict:}

As the previous discussion has revealed, no particular problems arise in respect of Permissive Licences, but with the restrictive licences which were presented to us (all of them in the GPL licensing group) a number of distinct points of conflict arise. Some of the points of conflict are clear. In particular, both the GPL 2 and the GPL3 and related licences are likely to be incompatible (or, at least, in the case of the GPL3, cannot safely be relied upon as being compatible) with FRAND licences, including, in all likelihood, FRAND-Z licences. In other words, it is probable that the GPL2 and GPL3 Licences would not be capable of allowing programs licensed thereunder to interoperate with EIF2 where there are unavoidable patents licensed on FRAND terms.

However, there are also less obvious potential areas of conflict which will become apparent as we now proceed to consider the terms of the examples of FRAND Patent Licences with which we were provided.

\section{FRAND Licence Conflicts:}

\section{(1) Royalty Free Licences.}

There being no royalty payable, it would clearly follow that no issue of incompatibility with the GPL Licences arises by reason of the existence of royalty payments. That, however, is by no means a complete answer, and it is necessary to look more deeply at the respective FRAND Licensing terms.

\section{(i) Microsoft Corporation: Royalty Free Business Process Execution Language for Web Services Specification License Agreement:}

The structure of this licence is typical of the Microsoft FRAND Licences. There is granted: first, a Copyright Licence in relation to the licensed work: second, a Patent Licence, and, third, a permission to distribute the Source Code. Each of the first two of these licences is non-exclusive, royalty free, non-transferable, non-sublicenseable, personal and worldwide, and the permission is stated to be nontransferable, non-sublicenseable and personal (though, clearly, it is also in effect non-exclusive and royalty free.) Because each of these licences is personal, it follows that, if a developer (developer A) originates, or modifies a work under the GPL2 or GPL3 terms, he has to be able to make that work available "as a whole" to downstream recipients. That he does by himself obtaining a licence (in the 
present instance) from Microsoft of the Royalty Free Business Process Execution Language for Web Services Specification. Thus, he is able to transmit (in the language of clause 2(b) of GPL2) the work as a whole, at no charge to developer B and any other person to whom he may wish to transmit it. However, if Developer B carries out further modifications and then seeks to transmit the modified work to another party, the benefit of the Microsoft licence in favour of Developer A does not transmit to Developer B, who would have to obtain his own Licence from Microsoft. Thus it would be argued that Developer A is unable to cause that the work which he publishes is licensed as a whole at no charge to "all third parties under the terms of this license."

As we stated above, there is a reasonable prospect that, applying a purposive interpretation, if the required result were achieved but as a result of the licensing structure, rather than the actions of developer A, a court would not regard developer A as being in breach - and, in any event, it might be said that it was Developer A's act in applying for the Microsoft Licence which did cause the whole work to be available. This, however, is something of a side-issue. The real question is whether the work is being made available under the GPL licence to "all third parties" (GPL2) or "anyone who comes into possession of a copy" (GPL3).

The obvious problem would be that any licensing by a developer to a licensee (be it a licence of the original work from the original developer to developer $\mathrm{A}$ or to developer B or to a downstream developer, a licence of the first modifications by developer A to developer B or a downstream developer, a licence of the second modifications by developer B to a downstream developer and so on) would be permitted under both the GPL and the Microsoft Licence, but, although the licensee could carry out his own modifications in respect of the GPL work, he could not do so in respect of modifications which would put him into breach of the patent licence and of the copyrighted material licensed by Microsoft without first obtaining his own licence from Microsoft. Because the particular Microsoft Licence is a FRAND-Z licence, the downstream recipient will end up with a licence from Microsoft of the unavoidable patent, but will not have got one automatically, which a court might be likely to determine is what clause 2 (b) of GPL2 requires.

Clause 5(c) of GPL3 stipulates: "You must license the entire work, as a whole, under this license to anyone who comes into possession of a copy." As already noted, if licensed under the GPL3, the GPL will provide the same licensing terms (and freedoms to copy and modify) to anyone downstream. In these circumstances, since the benefits of the Microsoft Licence will not extend downstream (but will require each recipient to apply for his own Microsoft Licence) it will also follow that the Microsoft Licence and clause 5(c) of GPL 3 are inconsistent with each other.

This is underlined by the terms of clause 2.3 (the Source Code permission) of the Microsoft Licence read in the context of clause 11 of GPL3.

Clause 2.3 of the Microsoft Licence provides for the insertion of a Notice, which clearly explains the effect of the Source Code permission:

"This source code may incorporate intellectual property owned by Microsoft Corporation. Our provision of this source code does not include any licenses or any other rights to you under any Microsoft Intellectual Property. If you would like a License from Microsoft (e.g. rebrand, redistribute) you need to contact Microsoft directly". 
This is inconsistent with clause 11 of GPL3 which requires that the source code should be "available for anyone to copy... under the terms of this licence" and the extension of the patent licence to downstream recipients "in a manner consistent with the requirements of this license."

In short, it is difficult to see how either the GPL2 or the GPL 3 Licence on the one hand and this Microsoft Licence on the other might be reconciled to each other.

\section{(ii) Microsoft Corporation: Royalty Free Business Sockets Direct Protocol License Agreement:}

This differs from the Royalty Free Business Process Execution Language for Web Services Specification License Agreement in that it does not contain a Copyright Licence, but it does contain a Patent Licence and a Source Code Distribution permission which are in similar terms to the Business Process Execution Language for Web Services Specification License Agreement. Our comments are as in respect of that last-mentioned Licence Agreement.

(iii) Microsoft Corporation: Royalty Free Sender ID Patent License Agreement:

This contains a Patent Licence in similar terms to the other two Microsoft licences examined above. The Source Code Distribution Licence is somewhat differently worded, but is still non-transferable, non-sublicensable and personal. The position of the Agreement in relation to the GPL2 and the GPL3 is as noted above.

\section{(iv) Microsoft Corporation: Structured Storage License Agreement:}

In common with the Business Process Execution Language for Web Services Specification License Agreement, this Licence consists of a Copyright Licence, a Patent Licence and a Source Code Distribution permission. The terms of the Copyright licence and Source Code Distribution permission are similar to the Business Process Execution Language for Web Services Specification Licence Agreement and raise the same issues in relation to the GPL2 and 3 Licences, as does the Company Implementation Patent Licence. The Company Toolkit Patent Licence imposes additional obligations on the Licensee to impose additional restrictions on the end users. This is likely to be inconsistent with clauses 7 of GPL2 and 12 of GPL3.

(v) Microsoft Corporation: Royalty Free Web Services Security Specification License Agreement:

The analysis here is as in respect of the Business Process Execution Language for Web Services Specification License Agreement.

(2) Royalty Payable Licences:

(i) British Telecommunications plc: Licence Agreement for the use of a CCIT Approved Algorithm in V42 BIS Modems:

The architecture of this Agreement is that it grants a Licence for the use by the Licensee of the Licensor's essential statutory IPR, for the use and sale of "Licensed Products". The term, "Licensed 
Products" is limited to "apparatus, modems and like equipment and shall not include components such as (but not limited to) microchips or stand-alone software which embody the Licensor's proprietary intellectual property, except....” [emphasis added].

So long as the developer is selling (say) a modem, there is not a problem; but as soon as he is seen to be conveying (in the extended meaning of that word in the GPL3) software, there is an insuperable incompatibility between the GPL freedoms and this BT Licence Agreement.

Further and in any event, even if that issue might be overcome (though we cannot see how), there remains a substantial problem as a result of the levying of a Royalty. As explained above, this is likely to be inconsistent with both the GPL2 and GPL3 Licensing terms.

An interesting further issue is that clause 2 provides (inter alia) that the licence terminates when the IPR ceases to be essential. Essential is defined as meaning "not possible on technical grounds to make, sell or operate equipment which complies with the Standard of any part thereof without infringing that IPR." This raises the intriguing possibility that, even if the BT Licence were otherwise compatible with the GPL2 or 3, there might come a date on which it would cease to be compatible the date when the patent ceases to be unavoidable. It is at least arguable that this future possibility closes down the perpetual freedoms under the GPL2 and 3 (both of which apply for the full copyright term) thereby rendering the BT Patent Licence presently incompatible.

\section{(ii) MPEG-2 Patent Portfolio License:}

The essential patents contained in the MPEG-2 standard are owned by a number of different proprietors. This Licence is in reality a series of licences of individual patents. The specific terms of each of the licences differ to some extent from each other, but all share the characteristic architecture of being a grant of a licence or sub-licence to the grantee for his own use only, which gives rise to the same problem with the GPL 2 and the GPL3 as is referred to above: namely that it is not a licence for all to use. Each would-be user requires to obtain his own licence of the Essential Patents. Furthermore, some, though not all, are licences requiring the payment of a royalty which is related to the distribution of the work. As explained above, payment of a royalty at all is inconsistent with clause 2 b) of GPL2 and clause 11 of GPL3. Additionally, such a requirement would be contrary to the specific provision of clause 11 prohibiting an arrangement whereby "the Licensee pays a royalty related to the extent of the licensee's conveying of the work."

\section{FRAND Licensing - Compatibility with EIF2:}

Aside from the issue of the compatibility of FRAND Licensing with Open Source Licensing, there may also be an issue regarding the compatibility of individual FRAND licences with the EIF2. In particular, there is an assumption in EIF2 that a given developer who wishes to utilise the standard will have a legal entitlement to be given a FRAND licence of unavoidable patents. It may be worth examining that assumption.

Where a manufacturer uses a standard in a product which includes unavoidable intellectual property rights that are the subject of a FRAND licence, and the manufacturer is unable or unwilling to obtain 
a licence from the owner of the unavoidable patent, but continues to manufacture products that use the standard, then he will be infringing the rights of the owner of the intellectual property. In these circumstances, it is clearly essential for the whole scheme of FRAND Licensing of unavoidable patents that the manufacturer can be assured that a FRAND Licence will be granted. What assurance does he have that he will be able to obtain such a licence?

Relying upon a hope or an easy assumption is not adequate. Manufacturers have been known to allow standards to be developed without disclosing that they have patent rights, and thereafter, in a "patent ambush", asserting those rights against persons implementing the standard in order to extract abusive royalties, as occurred, for example, in the Rambus case (Official Journal C030, 06/02/2010, pages 17 and 18).

One level of assurance may lie in self-regulation. In particular, when industry Interoperability standards, such as those developed by members of the European Telecommunications Standards Institute (ETSI), unavoidably include the intellectual property rights of others (usually from within the membership organisations), such standards setting bodies have invariably adopted Intellectual Property Policies that govern how the body will take into account those intellectual property rights that are utilised in adopting a standard. For instance, ETSI has a policy relating to the disclosure of essential intellectual property rights and rules regarding the licensing of such intellectual property rights on FRAND or RAND terms. Members are generally required to inform the standards body of their intellectual property rights within an appropriate time frame, and to volunteer to undertake to grant licences on FRAND terms and conditions. A further example of such a standard is the MPEG2 standard adopted by ISO/IEC JTC 1 and The International Telecommunications Union, which is the standard in respect of which the MPEG-2 Patent Portfolio License referred to above is issued.

How this works is illustrated in the litigation in the United States, Nokia Corporation v Apple Inc. (US District Court, Delaware 1:09-cv-00791-UNA). In that case, Nokia holds a number of US patents which are essential to the implementation of the GSM, the UMTS and the IEEE 802.11 Standards. Nokia declares itself ready and willing to grant FRAND Licences of those patents to Apple, but claim that Apple is refusing to pay the required royalty, accordingly does not have a licence and is therefore infringing the patent.

The GSM and UMTS standards are European standards developed under the patronage of the European Telecommunications Standards Institute (of which both Nokia and Apple are members), whose rules require the disclosure of essential IPR and its licensing on FRAND terms. The mechanism by which this is sought to be achieved is rule 6.1 :

\footnotetext{
"When an essential IPR relating to a particular standard or technical specification is brought to the attention of ETSI, the Director-General of ETSI shall immediately request the owner to give within three months an irrevocable undertaking that it is prepared to grant irrevocable licences on fair, reasonable and non-discriminatory terms and conditions under such IPR to at least the following..."
}

In fulfilment of its obligation under this rule, Nokia published a Declaration in the following terms:

"The Signatory has notified ETSI that it is the proprietor of the IPRs listed above and has informed ETSI that it believes that the IPRs may be considered essential to the Standards 
listed above. The signatory and/or its affiliates hereby declare that they are prepared to grant irrevocable licences under the IPRs on terms and conditions which are in accordance with clause 6.1 of the ETSI IPR policy, in respect of the Standard, to the extent that the IPRs remain essential.....

"The construction, validity and performance of the Declaration shall be governed by the laws of France."

Nokia's position, in its Complaint, is that it is willing to fulfil that obligation, but that Apple is refusing to compensate Nokia on FRAND terms. The text of the Complaint is available at:

http://www.scribd.com/doc/21458614/Nokia-vs-Apple-Complaint

Apple responded on several fronts (including claiming that Apple did not infringe the patents, that the patents are not essential, and counterclaiming for alleged breaches by Nokia of certain Apple Patents) but, so far as relevant to the present discussion, Apple maintained that the terms on which Nokia was prepared to offer a licence were not fair, reasonable and non-discriminatory. Apple's Answers and Counterclaim are available at:

http://www.scribd.com/Nokia-Apple-Counter-Suit/d/23997407

This example highlights what appear to us both the strengths and the weaknesses of typical FRAND licensing.

The clear intent of rules such as the ETSI rules, is to lead to an irrevocable undertaking which would be legally enforceable against the IPR holder. From the perspective of the Common Law jurisdictions, that intent may not be capable of achievement. In particular, under both English and Scots law, the general publication of such an offer would be an offer open for acceptance unless and until it is withdrawn prior to acceptance. (see Carlill v Carbolic Smokeball Company [1893] 1 QB 256; Hunter v General Accident Fire and Life Assurance Corporation 1909 SC (HL) 30). In order to ensure that an IPR holder does not withdraw the offer, it is said to be irrevocable, but if an IPR holder did purport to withdraw it, quid iuris?

The answer may differ in different jurisdictions. In Scots law, under the principle known as pollicitatio, a unilateral promise requires no acceptance, and a person making it may be bound by it:

\footnotetext{
"A promise is a pure and simple expression of the will of the party undertaking the obligation, requiring no acceptance, and still less requiring mutual consent... It appears to me that when a party, in terms of this letter, agrees to pay $£ 100 . .$. he is making a promise, and that by the bare act of his will thus expressed he undertakes an obligation to pay, which requires no acceptance." - Macfarlane v Johnston (1864) 2M 1210, per Lord Justice Clerk Inglis at page 1213.
}

This principle clearly applies to a promise to keep an offer open (Marshall and McKell v Blackwood (1747) Elchies sv 'Sale' No. 6, HL; A and G Paterson Ltd v Highland Railway Company 1927 SC (HL) 32 at 38). Accordingly, there would be no difficulty in Scots law regarding an offer to grant a licence on FRAND terms, and which is stated to be irrevocable, as being an offer which is open to 
acceptance by the general public and which legally cannot be withdrawn.

However, it would appear that Scots Law is different from the law of England and other common law systems as well as most of the civil law systems and the same result may not occur elsewhere. In particular, the position in English law would be that a promise to keep an offer open would not be legally binding unless the offer were made in a deed under seal, or the promisee has provided valuable consideration. (Chitty on Contracts (30th Edn) vol 1 \$3.022). The requirement for valuable consideration would not be met, leaving the requirement of a deed under seal. That would not be a problem if the undertaking were executed in England (a seal could be appended), but what if the granter chose to say that the offer were irrevocable but did not issue the offer under seal? (The undertaking to keep it open would not be binding.) Or what if, as in the Nokia case, the undertakings were issued under the law of France, or some other jurisdiction?

In the absence of a formal undertaking as under the ETSI rules, then if the appropriate licence agreement form were published by the IPR holder, that may still constitute a unilateral offer to enter into a bilateral contract: that is, the offer is open to anybody to sign and return the licence if they wish to, and if it is signed and returned, then both parties are legally bound by the terms of the licence. Should an IPR holder refuse to honour the provisions of the licence after a licensee has signed and returned it, then it is possible to argue that the IPR holder is estopped from resiling from the licence. However, this does nothing to address the question of irrevocability as in this example there would not be any Undertaking which even purported to be irrevocable.

Leaving aside the question of revocability, other problems arise.

First, not every IPR holder is necessarily a member of a relevant standard-setting body such as ETSI or the ITU, and will not be bound by the rules of such a body. Where the standard is being set by such a body, then if the body is aware of the existence of the essential IPR belonging to a nonmember, it may reasonably be anticipated that the that the body would not establish a standard containing such essential IPR without appropriate licensing from such non-member. However, one does not necessarily have any assurance that this is invariably so. In the event that the owner of the IPR is not bound by the rules of such a body, then it is difficult to see what legal compulsitor there may be upon the IPR owner to grant a FRAND Licence unless the IPR owner had voluntarily published such a Declaration as was published by Nokia under the ETSI rules.

Second, the example which we gave related specifically to the ETSI rules, under which the obligation of the IPR owner to undertake to grant FRAND licences is reinforced by rule 8.1.1 which provides that where an IPR holder refuses to offer FRAND licensing of unavoidable patents, there should be sought to be developed a standard which avoids that IPR, or (by rule 8.1.2) where no alternative is available, the standard should not be developed. However, not all standard-setting bodies will necessarily have the same rules.

Third, even granted the existence of such rules, this does not necessarily prevent a patent ambush as occurred in the Rambus case, and an ex post facto remedy founded in EU competition law is not as satisfactory as preventing the mischief in the first place.

Fourth (and in our view the greatest weakness) is the imprecision of the term "fair reasonable and non-discriminatory". What is "fair" to one person may not be seen as "fair" to another. This problem 
is thrown into particular relief where the FRAND Licence requires the payment of a royalty. This is not a merely theoretical observation as, in the Nokia $v$ Apple litigation it is at the heart of the subject matter of the dispute. In paragraph 2 of its Answers, Apple asserts that it "has the irrevocable right to be licensed to those patents on F/RAND terms".

It appears to us that this assertion exposes what may be a fatal flaw in the ETSI scheme and, it may be, other FRAND licensing schemes. It is a truism that a contract requires consensus on the essentials, one of which is price. Thus if an IPR holder offers to make a FRAND licence available at a price of, say, $£ 1000$, that is capable of being met by an acceptance and producing a consensus. However, if the offer (as it is in the undertaking) is merely to charge a "fair" price (and/or to grant a licence on terms which are "fair, reasonable and non-discriminatory") a purported acceptance of that offer would not create a contract as there is no consensus on what, precisely that price is, and/or those terms are, or, at least, a consensus on a mechanism for the objective determination of such terms (for example by providing a formula, or, alternatively, an agreement that the price or terms would be such as are set by an independent third party). It is at best merely an offer to treat. In these circumstances, it would seem to us, as lawyers in the two main UK jurisdictions, to be a leap of faith for Apple to assert that it has a legal right to the grant of a Licence, though we should stress that we express no view on whether such a position might be tenable under the law of the United States Federal jurisdiction in which the dispute is being litigated. Any such speciality apart, in our view it is not possible to pretend that there is an agreement where there is none.

Even if it could be asserted that there is a right to be granted a FRAND licence where there is no agreement as to its terms, or where an IPR holder is offering a licence which it asserts is fair, reasonable and non-discriminatory in its terms, but the potential licensee claims that it is not, then that assertion is a recipe for litigation.

In short, the EIF2 in calling for "Intellectual property rights related to the specification [to be] licensed on FRAND terms" may only be restating the problem, rather than providing an answer, given the scope for interpretation as to what FRAND terms may constitute and the legal uncertainty surrounding Licensees being able to compel by law the grant of licences which may unequivocally be regarded as FRAND licences.

A further issue arises from the possibility of different interpretation in different jurisdictions. We have already commented upon the difficult issues surrounding irrevocability of an offer to grant a licence (which is likely to be free of problems only if the offer were governed by the law of Scotland). Additionally, there are two recent cases which (apart from the issue of irrevocability) throw into question the effect of such an offer.

The Orange Book case (KZR 39/06) in which the German Bundesgerichtshof (Federal Court) handed down its decision on 6th May 2009, related to a refusal by patent holders, Philips and Sony, to grant a FRAND licence of IPR in the CD-R standard in favour of the defendant, a would-be licensee under such a licence. At the core of the action were issues of competition law (rather than the private contract law issues which we discuss above). It was maintained by the defendant that, by refusing to grant a Licence, the plaintiff was abusing a dominant market position. The court found, in principle, that this was a relevant contention: 
“a) The defendant named can make a claim arising out of a patent against the plaintiff patent holder's default in respect of an improper use of a market dominant position if he refused to conclude with the defendant a non-discriminatory patent licence without limiting conditions." (See summary on page 1 of the judgement and also paragraph 27).

The court also found that before the Patent holder could be regarded as having acted improperly, the defendant would require to have made an unconditional offer to enter into an agreement in terms which the patent holder could not reject. The patent holder would not be able to reject the offer if to do so would "result in his infringing the prohibition on discriminatory and limiting conditions". In other words, if the would-be licensee makes an unconditional offer to accept a FRAND licence, the patent holder is required to accept it, and if he does not, he lays himself open to a claim by the would-be licensee.

However, the court also held that the defendant was required to act as though bound by the licence, abiding by the conditions attached to it, and, in particular actually paying the royalty due under the licence (paragraph 29). It is clear from the rest of the judgement, especially 33, that this does mean actually paying, rather than holding oneself out as willing to pay (presumably with the money being paid into some form of Trust account if the patent holder refused to accept payment).

The case was very much seen through the lens of German competition law. In particular, this is seen from paragraph 30 :

\footnotetext{
"The applicant must have made an acceptable offer of reasonable contract conditions which the holder cannot reject so the applicant cannot reasonably deal with similar enterprises or hinder him unfairly, as would be generally recognised. The market dominant holder is not obliged himself to offer permission for use of the invention: only if he turns down an offer to conclude an agreement on non-limiting or discriminatory conditions does he make improper use of his market dominant position. The use of a patent by an enterprise which is not prepared to enter into a licence agreement on such terms may not be tolerated."
}

However, the underlying contractual analysis seems to be that there is no obligation for the patent holder himself to offer to grant a FRAND licence, but on competition law grounds, could not refuse an offer to accept such a licence on FRAND terms. This analysis did not address the questions of contractual rights arising from undertakings to grant FRAND licences, which questions we address above. Indeed, it proceeds upon the specific assumption that there is no licence granted but that the would-be licensee has to behave as though there were.

This falls to be contrasted with the case in the Netherlands of Koninklijke Philips Electronics N. V. $v$ SK Kassetten GMBH \& Co. KG (17 March 2010). In that case, the circumstances were similar (and even one of the parties, Philips Electronics NV was the same). The would-be licensee, founding on the Orange Book case insisted that it was entitled to a FRAND licence under cartel law. The Dutch Court was not persuaded. The court found that there was an infringement by SK of Philip's patent, then continued (\$6.19):

"SK's argument that it is entitled to a licence under EP 238 on Fair Reasonable and Nondiscriminatory (hereafter: FRAND) terms, cannot lead to a different conclusion. To the 
contrary of SK's belief, the alleged entitlement to a FRAND-licence is not a permit to infringe upon Philips' patent rights. If the alleged entitlement would have actually been converted into a licence, SK would naturally be free to use the patented technology. However, as long as SK does not have a licence, there is in principle no ground to allow SK the use of the patented technology, nor to prevent Philips from enforcing its patents."

For the purposes of the present discussion, the court's reasons are particularly apposite:

"6.21 Allowing the use of patented technology or preventing the enforcement of a patent right on the basis of a mere entitlement to a FRAND-licence, would moreover lead to legal uncertainty. As long as the alleged entitlement is not converted into an actual licence, it is uncertain for both parties if the alleged entitlement is justified, let alone that it is clear what the licence terms will be. There will be frequent cases of such uncertainty, as parties regularly will have different opinions regarding the answer to the question which terms, and especially which royalty rates, are FRAND. Therefore, also in view of legal certainty a system is desirable wherein the right to enforce a patent only stands after a party actually has a licence." [emphasis added].

Finally, in justifying its decision, the court stated:

"6.25 The Court is aware that with the above mentioned ruling it deviates from the criteria which have been developed for the assessment of so-called FRAND-defences by the German Bundesgerichthof (hereafter: BGH) in the Orange Book decision (BGH 6 May 2009, KZR 39/06, $b 9$ 7936). According to the BGH, in an infringement case, the defence that the defendant is entitled to a FRAND-licence holds water if - in sum - the defendant has unconditionally offered the patentee to take a FRAND licence and the defendant is already executing the conditions thereof, in so far as it concerns the royalty obligations, if so wanted by putting up security. From the foregoing it follows that the court is of the opinion that this decision of the BGH applied to the Dutch situation (i) flies in the face of patent law (compare findings 6.19 and 6.20) (ii) brings about legal uncertainty (compare finding 6.21) and (ii) is unnecessary for the protection of the legitimate interests of the defendant (compare finding 6.22 and 6.23). [..]"

It seems to us that the section which we have emphasised in $\$ 6.25$ effectively exposes the weaknesses which, from a common law perspective, we have highlighted above. A mere agreement to agree is no agreement: first, until a licence is actually granted, there is (self-evidently) no licence; second, so long as the actual terms of a FRAND licence are neither agreed nor capable of objective ascertainment, there is no consensus as to the terms of any such licence and there is no basis upon which a plaintiff might request a court to order the granting of any such licence; and, third, even if those hurdles might be overcome, in the final analysis FRAND terms end up as being whatever the patent holders would be prepared to grant as being FRAND terms, no more no less, unless some alternative compulsitor can be found in the relevant competition law to require a compulsory licence, but even then, it is at best uncertain whether the relevant court would allow the entitlement to a compulsory licence to be used as a defence in infringement proceedings unless and until such a licence is in fact granted. The German courts would allow such a defence, the Dutch courts would not, and what may happen in other jurisdictions is an open question.

That is not to say that it may not be possible to make a FRAND licensing scheme legally workable. 
As we have identified, the two major problems with the present regime are, first, having a clear statement of terms which, if accepted by a would-be licensee, would produce a consensus and not a mere "agreement to agree" and the second problem is to ensure that this offer, which has to remain open to all comers, is not withdrawn.

So far as the first problem is concerned, all that would be necessary would be that the Patent holder should publish the actual terms (including price, if any) on which the FRAND Licence is being offered. In order to prevent a very obvious abuse of this, there would require to be a role for the standard setting body in determining whether those terms would be fair, or, if not, then to avoid incorporating the patent in the standard. Alternatively, if it is thought that the standard may have a sufficiently long shelf-life as to make it inadvisable to set the terms at the start for all time, then, on the principle that a thing is certain if it can be made certain, the offer should stipulate that (for example) the terms will be such as are set from time to time by an appropriate third party, such as the relevant standard-setting body.

In order for this scheme to be workable, it would be indispensable that no standard-setting body should permit the creation of a standard involving embedded patents without there being in place internal rules having the effect described in the previous paragraph and which would bind all patent holders who wish to have their patents embedded in the standard.

So far as the second problem, irrevocability of the offer, is concerned, this might be achieved by requiring all offers to be expressly stated as being governed by the laws of a jurisdiction (such as Scotland) which recognises the legal enforceability of a term in an unaccepted offer not to revoke that offer. Alternatively, a similar result might be achieved where a contract is subject to English law under the provisions of the Contracts (Rights of Third Parties) Act 1999, although it is a precondition that a contract exists for a third party to have any rights under this Act (thus a contract could be established between the patent holder and, for example, the standards body, under which licence rights were explicitly granted to third parties by virtue of the provisions of the Act). Where there is an offer that has not been accepted, there can be no contract. The Act provides an exemption to the doctrine of privity, in that it permits a third party to obtain rights under a contract. The terms of the Act apply either expressly (under $\mathrm{s} 1(1)(\mathrm{a})$ ) or where a term purports to confer a benefit on a third party (s1(1) (b)):

\section{"1. Right of third party to enforce contractual term.}

1. (1) Subject to the provisions of this Act, a person who is not a party to a contract (a "third party") may in his own right enforce a term of the contract if-

2. (a) the contract expressly provides that he may, or

3. (b) subject to subsection (2), the term purports to confer a benefit on him."

The third party must be specifically mentioned in the contract for the provisions of s1(1)(a) to apply. For the third party to have the advantage of the second head, first, a benefit must be conferred on him (Prudential Assurance Company Ltd v Ayres [2007] EWHC 775 (CH), [2007] All ER 946, reversed [2008] EWCA Civ 52 on the ground that the contract restricted the claims of the third 
party). Whether such an intention existed would be a matter of construction (s1(2)). Second, s1(3) provides that the third party can be identified in the contract as a member of a class or as answering a particular description. It must be emphasised that the general rule is that a contract only binds the parties to it, and the Contracts (Rights of Third Parties) Act 1999 only refers to the acquisition of rights under a contract to which a third party is not a party. It does not deal with the question as to whether duties can be imposed by such a contract on a third party.

Without these safeguards, we fear that there is a risk that FRAND Licensing may be seen as a thing of smoke and mirrors.

\section{An Irresistible Force and an Immovable Object}

In the light of the foregoing analysis, it is possible to see the issues with greater clarity.

The EIF2 requires:

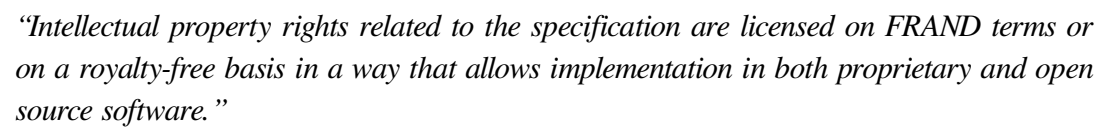

The first part of the requirement is for the IPR to be "licensed on FRAND terms or on a royalty-free basis".

This requirement conceals more than it lays bare. There is no legal certainty over what FRAND terms are, or may be, nor any mechanism to determine such terms objectively. Insofar as there exist rules and procedures laid down by standard-setting organisations to compel the granting of FRAND licences, these procedures may or may not be effective, and may lead to different results in different jurisdictions. Ultimately it may not be possible to compel the granting of such licences in private law, not least because of the inability to regard the use of the phrase "FRAND terms" as denoting a consensus. Even if, in certain circumstances and in certain jurisdictions the grant of a licence may be compelled under competition law, that is, at best, a cumbersome instrument, especially in those jurisdictions which do not admit of the right to use as entitlement to a compulsory licence defensively.

By the second part of the requirement, there is sought to be achieved a level playing field between proprietary and open source software - the IPR has to be licensed "in a way that allows implementation in both proprietary and open source software."

Such a level playing field can be achieved in respect of permissive open source licences and in respect of the EUPL, but cannot, as matters stand, be achieved in respect of the GPL2 and GPL3 family of licenses, the terms of which may prevent the "conveying" of software thereunder where there is not an automatic perpetual licence of the unavoidable IPR. The fundamental incompatibility lies in the architecture of the two licensing models - the GPL model is a cascade where, having granted the initial licence to the first licensee, the owner of the original IPR (in this case, copyright) does nothing further - subsequent licences arise automatically, whereas under the FRAND model the owner of the 
IPR (in this case, the Patents) grants a fresh licence on each transfer. The GPL requires that the patent licensing should conform to the same licensing architecture as the GPL model.

That is not to say that there could not be devised a model of FRAND licensing which could accomplish conformity with the objectives of the GPL2 and 3, but at the very least, the licences would have to be FRAND (and in the case of GPL2, FRAND-Z) licences and have similar "automatic grant" terms to those contained in the GPL, permitting the first licensee to transmit the benefit of the licence to the next and so on down the line, as happens under the GPL model. It may be questionable whether IPR holders would universally be prepared to agree such a model of licensing, though if a critical mass of them were, that might lead to a changed understanding of FRAND licensing which would make it compatible with the GPL licensing terms. However, it should be noted that any such onward transmission of the benefit of the patent licence would be effective only insofar as required to implement the standard.

If such a hypothetical alternative model might be achieved then it would be arguable that the objectives of the GPL would have been achieved, even though there may remain conflicts with the precise wording (for example, although there would be the required automatic downstream licensing, it would not arise "under this [i.e. the GPL] licence"). For full compatibility to be achieved, some revisal of the terms of the GPL would be required. However, such revisal could only occur were there to be a modification of the present opposition in principle of the GPL to patents. This may not be too likely.

Whatever the theoretical possibility of such an outcome, the fact remains that, because of the fundamental legal weaknesses in the existing FRAND model, it may be questionable whether the present model could ever satisfy the intentions which lie behind EIF2.

In short, as matters presently stand, EIF2 could be seen as incapable of full implementation: there is no legal precision as to what it requires (the reference to "FRAND terms") and it desiderates an outcome which, in relation to the GPL licenses cannot presently be achieved.

In its defence, it may be noted that although "FRAND terms" is a legally uncertain formulation, at a practical level the industry has always managed to muddle through, and, of course the GPL family of licences is by no means the totality of the Open Source licensing models, none of the rest of which cause the same problems, so, it could be argued, software developers could adopt one of these other licences. However, the economic reality is that (as the figures provided in the Brief disclose) $64.58 \%$ of the Open Source licences which have been adopted belong to the GPL family.

\section{The Questions Answered:}

In light of the foregoing, we answer the Questions asked of us in the Brief as follows:

1. Counsel are asked to consider what aspects of a restrictive open source licence (as typified by GPL2) would be impacted by a typical RAND licence, and whether this would be equally true for permissive licenses.

Clearly, where there is an unavoidable patent embodied in a standard, then, if a software developer 
writes software to operate with the standard, that will give rise to an infringement of the patent, unless the patent owner grants permission for the patent to be used, which is to say, licences the patent to the developer. Since such Licensing is usually on FRAND or FRAND-Z terms, the patent holder cannot choose to deny a licence to a software developer who seeks to use open source software. There is, however, a problem which arises by reason of the fundamentally different architecture of the "cascade" licensing of Open Source software under the GPL2 and GPL3, and the parallel licensing of software patents under the typical FRAND Licensing scheme. It is not a problem with the EUPL which, although having the same architecture as the GPL, does not attempt to fence it with restrictive requirements in the way that the GPL does. The problem with the GPL becomes evident in relation to the next question.

2. Counsel are asked to consider what operative provisions, if present within a RAND licence, would prevent the use of software under open source software licences (both restrictive and permissive), to implement solutions dependent on such RAND licences.

No problem arises from the terms of the EUPL and the permissive and hybrid licences which we have been asked to examine. However, problems do arise because of the fundamental incompatibility of the architecture of the GPL family of licences (as that architecture is reflected in the GPL licensing terms) with the existing FRAND model. In particular, if the granter of the GPL licence cannot provide the same automatic downstream cascade of patent rights as he can in respect of copyright, he cannot grant a GPL copyright licence. Furthermore, there is an additional incompatibility under the GPL2, and very substantial problems in relation to the GPL3, all as discussed above. Therefore, it is probable that the GPL2 and GPL 3 Licences would not be capable of allowing programs licensed thereunder to interoperate under EIF2 with standards containing unavoidable patents where there are unavoidable patents licensed on FRAND terms, though it might be an open question whether some of these issues could be addressed if the IPR holder were prepared to agree to the downstream transmission of the benefit of the licence.

3. Counsel are asked to advise whether the restrictions deemed to be present above would still be present if the RAND licence was made available on royalty free terms or if a royalty of zero was possible, if for example the royalty was based on a percentage of revenue.

As we explain above, the problem of incompatibility between the GPL 2 and GPL 3 terms and FRAND Licences of unavoidable patents embedded in standards is not restricted to cases where a royalty is charged. Therefore, although the removal of any obligation to pay any charge or royalty would address one of the concerns, there would still remain the fundamental incompatibility to which we refer in answers 1 and 2.

4. Counsel are asked to advise on the extent to which (if any) open source companies are in practice restricted from developing software where the implementation in question necessitates the infringement of unavoidable patents contained within an interoperability standard, even where RAND$Z$ or RAND licences are available in respect of such patents.

Of course developers cannot develop software where the implementation in question necessitates the infringement of unavoidable patents contained within an interoperability standard unless they have first obtained a licence from the patent owner. There ought not to be any such patents in respect of 
which licensing is on anything other than FRAND terms, and, accordingly a developer may readily obtain a patent licence and thereby avoid infringing the patent. In cases where FRAND licensing is not available (for example in the case of Patent ambushes) a remedy may be available in Competition Law.

The problem, however, is that, although the obtaining of a FRAND licence provides a complete answer for a developer who is using the EUPL or a permissive or hybrid licence containing terms similar to those in the licences which we have examined, such a solution is not possible in relation to restrictive licences belonging to the GPL family at least in the absence of agreement by the IPR holder to the downstream transmission of the benefit of the licence. Even with such an agreement, substantial problems may remain.

In summarising the outcome of our consideration of these licensing terms, we should also draw attention to the potential inadequacies in FRAND licensing schemes which are presently operated, namely the problem of offers of FRAND licensing terms which, though they say that they are irrevocable, may nonetheless be legally withdrawn at any time prior to acceptance and the problem of mere "agreements to agree" which fall short of disclosing any such consensus as would be necessary to form an agreement. We draw attention also to our suggestions as to how those matters might be addressed.

\section{Conclusion:}

Where, then, to go from here?

It is noteworthy that the EIF2 is largely an aspirational document. Its objective is that IPR should be licensed "in a way that allows implementation in both proprietary and open source software". Arguably, to allow the Commission's overriding objectives to be achieved requires the immovable object of the present FRAND licensing regime to give way to the irresistible force of Open Source licensing requirements or vice-versa, but this is not a legal argument so much as it is a political and economic one. It is not a legal argument because, in the final analysis EIF2 is not a legal document and if the lawyers get involved in the argument, they will fall to arguing about how far EIF2 is mandatory, and raise issues concerning open source licensing models that do not cause the same conflicts.

The argument, rather, is economic, social and political because of the plain defects in the present FRAND model which has no proper legal underpinning and in which, when push comes to shove, that which is fair is what the IPR holders are prepared to agree as being fair. It is economic, social and political because it is about policy decisions which require to be made by the Commission as to where the balance ought to lie between holders of IPR in unavoidable patents and those who seek to interact with the standards. Finally, it is economic, social and political because the overriding objective of the Commission - to "foster competition since providers working under various business models may compete to deliver products, technologies and services based on such specification." - is an objective which is, at once, economic, social and political. 
EIF2 is but a step in a continuing process. The attainment of the Commission's objectives is still all to gain or lose.

\section{THE OPINION OF}

Iain G. Mitchell QC; Stephen Mason, Barrister. 


\begin{abstract}
About the authors
Iain G. Mitchell QC is in private practice as an Advocate (Barrister) in Scotland. He was called to the Bar in 1976 and took silk in 1992. He is the Chairman of the Scottish Society for Computers \& Law, Chairman of the Faculty of Advocates Information Technology Group, Co-convenor of the Scottish Lawyers European Group, an Honorary Lecturer in the Institut für Informations- Telekommunikationsund Medienrecht at the University of Münster, Westphalia, and a Liveryman of the Worshipful Company of Information Technologists. He holds office as the United Kingdom representative on the Information Technology committee of the CCBE and is a member of the IT Panel of the Bar Council of England \& Wales and of the Scottish Courts Technology Forum. He is a member of the editorial committee of the International Free and Open Source Software Law Review. His other publications include the Scotland Chapter in Electronic Evidence ( $2^{\text {nd }}$ edition LexisNexis Butterworths, 2010). He is a member of the Church \& Society Council of the Church of Scotland for whom he recently completed work as a joint author of the major Report to the General Assembly: The Internet - In whose image? and is engaged in working on a similar project for the Ethical and Spiritual Development Panel of the WCIT. He is recommended in the Legal 500 for IT and IP Law and is rated in Band 1 for both IT Law and Public Procurement Law in the Chambers Directory. He has been invited to lead a Public Procurement Special Interest Group for the European Legal Network.
\end{abstract}

Stephen Mason is the author of Electronic Signatures in Law (3rd edition, Cambridge University Press, 2012) and general editor of Electronic Evidence (2nd edition, LexisNexis Butterworths, 2010) and International Electronic Evidence (British Institute of International and Comparative Law, 2008). Web site: http://www.stephenmason.eu 


\section{Licence and Attribution}

This paper was published in the International Free and Open Source Software Law Review, Volume 3, Issue 1 (September 2011). It originally appeared online at http://www.ifosslr.org.

This article should be cited as follows:

Mitchell, Iain G; Mason, Stephen (2010) 'Compatability Of The Licensing Of Embedded Patents With Open Source Licensing Terms', International Free and Open Source Software Law Review, 3(1), pp 25 - 58

DOI: 10.5033 /ifosslr.v3i1.57

Copyright (C) 2011 Iain G. Mitchell QC, Stephen Mason.

This article is licensed under a Creative Commons UK (England and Wales) 2.0 licence, no derivative works, attribution, CC-BY-ND.

As a special exception, the author expressly permits faithful translations of the entire document into any language, provided that the resulting translation (which may include an attribution to the translator) is shared alike. This paragraph is part of the paper, and must be included when copying or translating the paper.

$$
\text { (c) } \mathrm{BP}_{\mathrm{BV}}
$$

